\title{
Barriers Concerning Digital Inclusion in one São Paulo Public School: What Have Adolescents Been Learning on the Internet?
}

\author{
Claudia Dias Prioste \\ College of Education, University of São Paulo
}

\begin{abstract}
This paper presents findings from research on adolescents in one public school of São Paulo. The aim of this study was to analyze the existing barriers concerning digital inclusion and understand how adolescents have been using the internet, with special focus on what they are learning in the virtual world. Methodology: qualitative research based on psychoanalysis and critical theory. Data collection was carried out by participative observation in computer classes over a period of seven months. A questionnaire was administered to 67 students, ages 13 to 16. Results: the analysis was focused on three issues: connection, capability and content. It was observed a serious lack of ICT resources in the school: 21 computers for 700 students, resulting in insufficient connection time. Although $76 \%$ of students said they had internet access at home, most of them were digitally illiterate. Content most accessed by adolescent included shooter games, social networking, funny videos and pornographic websites. Conclusion: The main barriers identified concerning digital inclusion were low ICT connection in the pedagogical context; precarious levels of basic education; and above all, adolescents' virtual habits, largely rooted in trivialities. The vast majority of adolescents have not benefited from the internet in terms of learning, knowledge expansion or development of computer skills due to conventional usage practices encouraged by the culture industry. This is most prevalent in the area of gaming. Adolescents' activities in cyberspace were characterized by the fulfillment of voyeuristic, exhibitionist, and sadomasochist satisfactions which complicate the sublimation process and relevant symbolic exchanges.
\end{abstract}

\section{Introduction}

Information and Communication Technologies (ICT), especially the internet, greatly increases the opportunities for knowledge access. The dream of ubiquity, transposing the boundaries of time and space, the possibility of sensorial sensations in other dimensions, or to expand the limits of the body, has become possible with the help of technological devices. The "God of prosthesis" as Freud called the human being, has not measured efforts at expanding yours sensory and cognitive skills, however this pretentious progress brings with it new problems to be critically examined [1]. In the field of Education, ICT can be an important resource for the learning, but it also increases inequalities between those who do and do not reap its benefits.

During the last twenty years, governments have become aware of the digital inequality problem, which, according to Bradbrook and Fischer, is connected not only to the lack of access to ICT, but also deeper social and educational problems. They argue that mere access to ICT doesn't guarantee of digital inclusion, because it's essential to think about how the technologies can to improve the people's quality of life [2].

According to The Europe Advisory Groups, Einclusion is "the effective participation of individuals and communities in all dimensions of the knowledge-based society and economy through their access to ICT" [3]. Even if a large number of people are increasing the access to technology, it doesn't mean more participation in the relevant social issues.

To understand the complexity of digital inclusion is important to considerer some aspects that Bradbrook and Fischer summarize in 5 " $\mathrm{C}$ 's" key issues: Connection, Capability, Content, Confidence and Continuity. Connection is access to the internet and it should be considered from a home and community perspectives. Capability refers to ICT skills with the purpose of increase quality of life and employability. The third key issue is content, and it is crucial to promote access to suitable content on the cyberspace. Confidence is another essential point, because it is necessary to consider the motivations that drive people to go online. Finally, it's important think about the progressive learning, the continuous personal and community development [4].

Internet access in Brazil has been increasingly encouraged by public policies for digital inclusion. Brazilians children and adolescents from different 
social classes, who live in urban centers, have displayed their gadgets and accessed cyberspace. Most of them have internet connection in their home, cybercafé, online public centers or at the school. In 2005 there were only 13\% of Brazilian households with access to the internet, this rose to $31 \%$ in 2010 in urban area, although, this percentage is low when compared with the international scenario according the Internet Management Committee in Brazil (CGI.br) [5].

Despite efforts in public policies on digital inclusion, Brazilian public schools still have an important gap in terms of access to ICT. A national study of ICT in schools, carried out by CGI, showed that in Brazil, $81 \%$ of schools have technological structure, however these schools have, on average, 23 computers for 800 students. There is clearly a deep shortage of resources for ICT education. The CGI also notes that Brazilians have enjoyed a high internet bandwidth and higher network utilization presented via laptop or mobile phones. [6]

Notwithstanding the significant increase internet accessibility in Brazil, digital inclusion, in order to provide social participation remains a challenge in our country and the barriers are many, especially for the adolescents from low economic conditions. Internet access has caused deep changes in contemporary adolescents' lives, affecting social relations, leisure habits and even their relation with knowledge. Unfortunately, the most teenagers not seem to make a good use of the virtual world, and it's very important to examine this problem.

Pierre Lévy, a cyberspace anthropologist, believes that ICT creates a collective, autonomous, horizontal and revolutionary intelligence. This conception of intelligence emerged in the early nineties with the project knowledge tree, a digital communication system with collaboration assumptions based on recognition and mutual competency exchange. For Levy, the diffusion of intelligence could be facilitated through a technological prosthesis of perception, memory and communication, that would play out in cyberspace [7]. But our practice with youth education revel to us that the collective intelligence has not been accessible to everyone.

Adorno and Horkheimer's studies about the culture industry, conducted in the 1940s in dialogue with psychoanalysis, can help us in understanding why adolescents are fascinated by screens. The philosophers described how technological apparatuses could manipulate the unconscious and personal behavior. In Adorno and Horkheimer's vision, one of the functions of radio and movies was to occupy the mass population's free time with entertainment produced with the purpose of instilling conformity. They believed that the culture industry discouraged individuals from thinking about their real lives, waning forces of resistance and transformation [8].

The expression "culture industry", coined by Adorno and Horkheimer, is different from the idea of popular culture created by mass. Adorno considered that culture industry was the technological and cultural mechanism conducted by a concentrated economic administrative power, that using cultural products, aims at manipulating and encouraging the masses to engage in consumptions activities. For him: "It is industrial more in a sociological sense, in the incorporation of industrial forms of organization even when nothing is manufactured - as in the rationalization of office work."[9]. In this regard, cultural products are made with ideological purposes of controlling masses by unconscious process. According to Duarte, a Brazilian philosopher, Adorno's ideas are more relevant today in the context of globalization of the culture industry, because of the methods of manipulation implanted into the individual personality, like virtual reality, for example, which are technologically advanced and extremely powerful [10].

In reference to news communication technologies in education, Dufour, a French philosopher, considers essential that children have developed the symbolic capabilities before being exposed on digital sensory prostheses. He notes that many children have been abandoned in front of televisions and computers, and they could lose the possibility of developing the symbolic categories of time, space and person [11]. Fixing in the external images of devices without link with personal speech doesn't help the child organize his thinking.

For the philosopher Stiegler, new technologies are programmed to capture the full attention of youth, and this can be deleterious for cognitive functions in long term. The teenager spends excessive time concentrated on audiovisual devices, and his concentration on other activities becomes reduced. In reference to Plato, Stiegler draws an analogy between ICT and the notion of pharmakon, that is, technology working as medicine and poison at the same time $[12,13]$.

The effects of digital pharmakon need to be investigated, especially in the educational context. For this, is necessary to carry out empirical studies, avoiding a technophobic position or naïve beliefs about the digital world. Therefore, this study aimed to show how digital inclusion has worked in a São Paulo public school and what the adolescents think they are learning on the internet. Additionally it's important to understand the main barriers to digital 
inclusion especially for the teenagers from low social conditions.

\section{Research Questions}

How digital inclusion has been promoted in a São Paulo public school.

How the internet has been used for the adolescents? Has it been used to expand knowledge?

What are the main barriers to digital inclusion in the Brazilians public schools?

\section{Participants}

The observations were conducted in three groups in their last year of Secondary School. There were about 30 students in each class, but due to large abstention, only 20 adolescents, on average, attended classes. A survey was conducted on 67 adolescents, 37 boys and 30 girls, ages 13 to 16 . Most of them were of African descent, and lived in slums near the school. Some, despite being in their last year of Secondary School, were illiterate. The Brazilian public schools have had serious problems in children's literacy, thus, many teenagers leave Secondary School without being able to read and write correctly.

Despite reduced economic conditions, the digital devices and gadgets were hyper valued by adolescents studied. They frequently showed the new model of cell phones, and most of them $(76 \%)$ said they had computers with internet access at home. Probably it was a consequence of government credit programs in order to facilitate the purchase of computer by poor people.

\section{Methodology and data analysis}

The research was accomplished in the Computer Lab in a public school, where 21 computers with internet access were installed. All students in the Secondary School had fifty minutes of Informatics Class per week. This course had the purpose developing their computer skills and digital literacy. In the Informatics Class three groups were observed, once a week, during seven months in 2010.

The direct and participative observation had the aims of identify what ICT resources were available for the students; how the internet has been used in the educational context; and finally, what the adolescents have been learning in the virtual world.

In addition, a questionnaire was administered to 67 students, and interviews were done with the students known as "the most connected to the internet" as well as additional interviews with the teachers, coordinators, and principals.

Qualitative analysis was used to ensure a wider, more reliable vision of what young people have been doing while using the internet. Although we knew that it might not capture some important peculiarities, the questionnaire offered a general vision of the adolescents' habits and interests. Prolonged and close contact with the adolescents allowed us to catch more intimate and subjective subtleties of their virtual experiences, which would be imperceptible in a questionnaire. One of these peculiarities was the frequent access to pornographic websites which only became apparent during direct observations and in interviews.

To analyze data, we maintained a psychoanalytic perspective of "active listening" and of "participant eye" inspired by Amaral's studies concerning juvenile culture [14]. The researcher was attentive to the subjective elements evident in the relationship with the adolescents. Collaborating questionnaire, interviews, with observations, the researcher was able to make more comprehensive 'between the lines'. Data interpretations were based on the dialogue between psychoanalysis and critical theory.

\section{Results}

Connection, capability and content are the three focal points for our analysis. In respect of connection, within the school examined, there was a great shortage of ICTs resources. The 21 computers in the school's lab were not sufficient to promote digital inclusion for the over 700 students attending on a daily basis. Additionally, hardware was out of date and some computers were broken or without internet connection. Computer repair required bureaucratic procedures and was often ineffective. As a result of low ICT resources, we deduced that the adolescents' computer access time was insufficient for accomplishing any meaningful pedagogic activity.

Another problem concerning ICT access in the school was the time adolescents lost while moving to and from the computer lab. In fact, teenagers only had access to computers for approximately 25 minutes per week, often having to divide usage time with fellow classmates. In this short access time, they insisted on using the internet for fun: gaming, fighting, gossip sites, comedic videos, and even pornography. The protection software installed on school computers was flawed and did not prevent teenagers from accessing inappropriate content. The teacher alone could not control the activities of students on computers. Outbursts and violence were 
prevalent among students in the classroom, and it was very complicated for the teacher to manage behavior. Under these conditions, it is hard to believe that children and adolescents can learn ICT skills at school.

Lack of technological resources and deficiency in computer maintenance are issues which need to be addressed in Brazilian public schools. According to CGI, "the average of 23 computers per school has been reduced to only 18 in operation (...) in the Northeast, only 13 computers were connected" [15] in schools with an average of 800 students. It is important to note that there aren't enough computer maintenance technicians, and this responsibility is often transferred to the teacher.

Aiming to increase resources for digital inclusion, the Brazilian government, in 2007, initiated an experimental project called UCA (Project One Laptop per Child) in 5 schools. In 2010 this project was expanded to 300 schools, which were selected to receive one laptop per student [16]. However, evaluation reports concerning this experiment have demonstrated that structural problems persist. There continues to be a lack of basic necessities such as furniture, electricity and network bandwidth sufficient for all students to simultaneously access the internet. Moreover, there are serious problems with hardware, software, and unrepaired laptops [17].

Concerning the second point in this essay, capability, it was observed that most of adolescents studied could be considered digital illiterates, even though the school's curriculum offered a specific course aimed at developing ICT skills. Even more notable, the students observed had participated in this course for more than three years. According to Bradbrook and Fischer, ICT literacy is defined as the ability to use hardware, software and networks, as well as the ability to search, find and evaluate information in the virtual world [18]. We noticed that adolescents had great limitations in this area. Most of them were unable to save a file correctly in the instructed location, nor create a personal blog following directions provided by a do-it-yourself website. They also were unable to understand spellcheck indicators in text editing software, indicators normally understood intuitively.

The deficiency in technological capabilities observed in this study, contrasts with the high interest in computers, cell phones and the internet shown by adolescents. Furthermore, it's important to note that $76 \%$ of adolescents say they have a computer with internet connection at home. They also commented on enjoying showing off their gadgets to peers. For young people, these become status symbols. Thus, we would expect that these adolescents would be capable of developing certain technological skills on their own. Why doesn't this happen?

Young people's interest in cyberspace, stimulated by the cultural industry, can undoubtedly inhibit learning. Therefore, the third aspect in this results analysis is content accessed by adolescents. According to answers given in questionnaires and interviews, adolescents prefer to use the internet for the following activities: chatting on social networking sites, playing video games, listening to music, watching videos and accessing pornographic sites.

These results also revealed stark differences between male and female participants relative to website preferences. Girls were more likely to visit social networking and celebrity gossip websites, whereas boys generally accessed gaming and pornographic websites. It's important to highlight that some boys, despite living under precarious economic conditions, were willing to pay for virtual products in games to obtain advantages and increase their status.

This mapping of adolescents' habits and interests in the virtual world revealed that they use the internet more often for diversion than for expansion of knowledge. This data correlated with other Brazilian studies on children and on the habits of young people and internet use, which also demonstrated more frequent accessing of social networking sites, gaming sites and short videos, with less importance placed on internet use for learning purposes [19].

The survey, conducted by CGI, revealed that "only $11 \%$ of students say they learned to use a computer and the internet with a school teacher or educator. Learning from relatives, friends or others with whom they have a personal relationship, was most frequently reported (43\%)." [20]. Without adult intervention, adolescents remain connected only to content shared within peer circles. In this case, generally, they were eager to discover how to kill more monsters in a video game, manipulate a program to get more "lives", type faster, show their photos on social networking sites, or find shocking pornographic images. During the interviews, the adolescent showed interviewers the sites which they commonly visited: gaming sites, YouTube, social networking sites, and also chats rooms with erotic pictures and videos. These chat rooms contained zoophilia, child pornography, and even instructions on how to rape a woman or carry out a kidnapping. We observed that websites created exclusively for adult viewing are easily accessed by children and adolescents due to a lack of government-imposed internet restrictions. 
When asked what they had learned on the internet, many adolescents said they had not learned anything (16\%), as they simply use the internet to play and "chat". The most common answer was that internet use taught them to type faster (26\%). They also mentioned acquiring general knowledge (22\%), and knowledge resulting from research related to school assignments (17\%). Additionally, a few adolescents said they accessed foreign languages learning resources, and gained basic computer skills.

The lack of ICT resources in the school combined with serious problems in basic literacy; contribute to students not being able to absorb instructional information in computer classes. Consequently, they have difficulty in using the internet for learning purposes while at home. It was observed that adolescents had serious limitations in reading and writing ability, and virtual habits were reduced to stereotypical shooter games or basic communication, activities which do not require elaborate cognitive competencies or computer skills.

A national study on ICTs in Brazilian schools showed that the use of technologies for learning purpose is rare. "About $69 \%$ of students have never conducted a science experiment with the help of an ICT, 55\% have never used them to give a presentation in their class, $42 \%$ have never played educational games" [21]. This research also reveals that teachers have not been sufficiently trained for introducing ICTs into their classrooms. Most of them have limited computer and internet use skills themselves. This lack of ICT use for in-school learning purposes also makes it more difficult for young people to change virtual habits propagated by the culture industry.

\section{Discussion}

According to Bradbrook and Fischer, digital inclusion refers to the use of ICTs to enhance quality of life and employability, thus, it is important to develop e-learning skills: the ability to use the internet to solve real world problems [22]. We observed that the adolescents studied did not obtain concrete benefits from ICTs in their lives. Time spent on the internet is focused on recreational activities and neither contributes to real-life problem solving nor to the development of necessary skills required for adulthood.

The adolescents studied have not been able to take advantage of the virtual world for three reasons: low quality in basic education in Brazilian public schools, lack of technological resources in the educational environment, and cultural industry influences on virtual habits. These influences can potentially limit personal development and the ability to explore knowledge available online.

Although obsession with the virtual world appears to be more common in early adolescence, the compulsion for screens (computer, television and cell phone screens) is forged in early childhood. Nowadays, babies have electronic toys with screens and buttons, which when pressed, emit sounds and visual stimuli. Numerous gadgets have replaced imaginative role playing. Thus, balls, dolls, toy soldiers, wooden blocks, marbles and other toys have been incorporated into digital games. Childhood activities have been technologically reworked by the entertainment industry. And, beginning in early adolescence, students are well prepared for the consumption of audiovisual products, to which they have become accustomed. Duarte, in his analysis of the global cultural industry, observed that virtual reality has been manipulating esthetic tastes in important ways, as well as contributing to the expropriation of thinking, attaching the subject only to sensations [23].

Students in São Paulo's public schools spend, on average, less than five hours per day in the classroom. And time outside of school, generally, is not used for homework purposes, research or cultural or sporting activities, even when these activities are required or readily available. It was observed that, inside of the same building where classes occur, there is a sports center, a library, a theater and a community center for digital inclusion, with free access to internet and computer courses. However, the adolescents showed no interest in activities provided in these spaces.

It was observed that adolescents spend much of their free time online, engaged in shooter games, instant messaging, and accessing pornography and celebrity gossip websites. Consequently, they often fail to do homework, scholarly research, or engage in sporting activities. Most parents work during the day and are unable to monitor the activities of their children. Without adult supervision, teenagers prefer to stay at home on the computer or go to a friend's house to access the internet. Many times, they prefer sit in front of television or computer screens rather than involve themselves in real-life social interactions.

For adolescents, at a unique developmental moment, the narcissistic and perverse-polymorphic satisfactions offered by many sites on the internet can be extremely attractive. These satisfactions, however, carry a cost. In virtual games, adolescents have found sensorial stimulation and a source of 
fulfillment unparalleled. Destroying imaginary enemies, they are able to prove that they are "the best", and in so gain status and recognition from their peers. In pornographic chat rooms, teenagers are stimulated by voyeurism, exhibitionism, and sadism. On celebrity websites, girls live the fictional life of stars, and on social networking sites, they are able to post their preferred star's style for their virtual peers to see. In summary, omnipotent, voyeuristic, exhibitionistic and sadistic fantasies have been stimulated in cyberspace. These fantasies guarantee considerable and immediate satisfactions; however they may pull energy away from educational activities.

The increase in cyber addiction cases indicated by Hautefeuille and Véléa is suggestive of how some adolescents have become trapped. According to these researchers, adolescents are attracted to the virtual world and the prospect of feeling fulfilled, a sensation difficult to experience in real life. They are also attracted to the sense of recognition they receive from virtual peers [24]. Addictive behavior in cyberspace is more common than we imagine, and it is not restricted to young people with a history of mental disorder. We have observed in this study, a large percentage of the adolescents reported avoided doing homework, sleeping, or even going to school, so that they could continue surfing the internet. Such habits hardly seem the product of collective intelligence.

In light of these findings, it is clear that these youth rarely acquire knowledge or other significant competencies on the internet. The idea of collective intelligence proposed by Levy seems supplanted by stereotyped and perverse habits, coming closer to collective ignorance. Amorim, in her analysis of the knowledge tree, observes the tendency of substituting knowledge by recognition of relationships whose virtual pairs are tied in specular and narcissistic relationships. In valuing a presumed personal abilities exchange, as Lévy proposes, one risks ignoring the hierarchy of knowledge, as well as criteria of ethics and truthfulness of information [25].

Although the cyberspace anthropologist has the merit to begin extensive studies on cyber culture, it seems that Lévy hasn't been paying attention to the increased psychological power of cyberspace in directing the interests of users to virtual trivialities, thereby providing greater economic benefits for the audiovisual cyber-industries.

In the twentieth century, Freud observed the influence of technological progress on psychic functions. He postulated that the human mind does not remain the same in the midst of scientific progression. Some psychic functions, he argued, emerge or change simultaneously with these transformations. The human being is, in his words, a "god of prosthesis, (who) recreates his own motor or sensorial organs, or enlarges the limits of their functions". Such attributes, however, do not guarantee greater welfare [26]. The fundamental drives of life and death (Eros and Thanatos), coexist within technological creations. Thus, education professionals should not be naïve, but aware of the ideological forces that act furtively in the virtual world, destroying pathways to knowledge.

It is impossible to deny that important enterprises have been developed through online collaborations, and that many of them are the consequence of youth initiatives. Nevertheless, the websites which facilitate meaningful knowledge exchange can, without ethical supervision, also spread nonsense and even encourage crime. It is astonishing to know just how easily adolescents have access to pornographic sites and chat rooms, which exhibit extremely strong images of pedophilia and zoophilia as well as violence against women and children. Most of the aforementioned scenes were found in a chat room, on a site supported by the most important newspaper in the city of São Paulo. Many adolescents often visit these chat rooms because of sexual curiosity, but haven't the slightest notion of the psychological risks involved. It was staggering to discover how profit interests prevail in cyberspace at the expense of education and human values, even in companies seemingly geared toward public service.

Adorno and Horkheimer identified some forms of psychological manipulation put into action by the culture industry. They highlighted amusing and the expropriation of thinking capabilities, culminating in the weakening of the ego and conformism to the status quo [27]. Regarding the first aspect, in this research with adolescents, it was noted that constant fun is the priority, as a preemptive avoidance to boredom. A supposed happiness associated with entertainment and the possession of objects of consumption has become an obligation for adolescents. In this context, the internet plays an important role, because in cyberspace there is an endless supply of enjoyable, ubiquitous and inexpensive activities, which favor self-exhibition. Escaping boredom is also an attempt to avoid anxiety and the frustrations felt when facing life's demands. It is worth remembering that to have fun, in this sense, is to not have to think, and the global cultural industry has dealt well with this task. People are directed to lose contact with their subjectivity and their real-life experiences, as emphasized by Adorno and Horkheimer [28]. 
The ideological mechanisms acting through psychological manipulations in the socialization process of the person signaled, since the forties, changes in the libidinal economy. Stiegler argued that human beings' libidinal economy has been increasingly controlled by a technological psychopower. As a result of this pharmacology of media, there is a reduction of libidinal energy for cognitive processes and a tendency to fix the person into a state of minority, with neither personal nor collective responsibility. The philosopher was inspired by Kant, concerning concept of minority, in demonstrating the difficulties of contemporary individuals in the application of reason and responsibility, characteristics associated with persons of legal age [29]. For Stiegler, technocratic logic has led the human being to a zero degree of thought because his/her libido has been technologically exploited. Therefore, psychic energy sublimated in social relations is instead redirected toward audiovisual devices [30]. This tendency was easily identifiable in the adolescents studied. Most of them had attention deficit and impulsive behavior disorders. They acted without thinking about personal or collective consequences, resulting in a confusing and violent climate within the classroom. They tended to imitate stereotypical behaviors from comedic television programs, usually with sarcastic and aggressive expressions. The interpersonal conflicts were largely irresolvable through discussion and reflection, due the impulsivity of the adolescents. It would be naïve to believe that the impulsive and aggressive behaviors observed were natural characteristics of youth. The connection between the mimetic behavior and audiovisual products that teenagers consume daily was clear.

Voyeuristic, exhibitionist and even sadomasochistic curiosities are stimulated in online activities, especially in video games and on pornographic and social networking sites. These perverse polymorphic drives, present in all human beings in a variety of intensities, can be the cause for adolescents' fixation on sites of this sort. In psychoanalytic theory, it is considered that a certain portion of driving forces should be sublimated by intellectual activities. Nevertheless, if the teenager has not developed a good symbolic capacity in childhood, as Dufour [31] proposes, he will be unable to sublimate his polymorphic perverse driving forces by intellectual activities. In this case, his tendency is to remain in a state of continuous stimulation of the senses.

According to Amaral, schools should be more prepared to work with adolescents. Teachers need to understand the multi-sensory dimension in which these adolescents are embedded, and understand the cultural aspects at play in the educational relationship [32]. Since the internet is an intrinsic part of contemporary youth culture, it is indispensable that schools provide access not only to ICT, but also to pedagogical resources that can guide adolescents to pursue knowledge-increasing virtual activities.

\section{Conclusion}

Digital inclusion in the public schools of São Paulo has significant obstacles to overcome, the first of which being the lack of ICT resources due to insufficient devices, inefficient computer maintenance and a lack of effective teacher training. Secondly, with a precarious level of basic education, it has been difficult to development adolescents' computer skills and to promote the use of cyberspace for knowledge expansion and selfimprovement. However, the main barriers concerning digital inclusion are, indubitably, adolescents' interests and the virtual habits encouraged by the culture industry, primarily in online gaming, an area eager to exploit them financially.

For the vast majority of the adolescents studied, the internet has not been a vehicle for increasing knowledge. Online social interactions have not fostered the development of relevant life skills. Generally speaking, adolescents, especially boys, stay in perverse-polymorphic virtual relationships, in which omnipotent and sadistic fantasies prevail. The virtual libidinal investment seems to be characterized by narcissism, that is, centralized in the subject himself, or in specular relationships which often inhibit the possibility of sublimation through socially relevant symbolic exchanges.

The most important developmental tasks during adolescence are liberation from parental authority, construction of social connections and acquisition of abilities and responsibilities for adult life. Nonetheless, in the contemporary world, with incisive mediation made by market and media technologies, these developments, frequently, are obstructed. In the virtual world, teenagers are encouraged to remain engaged in the fulfillment narcissistic satisfactions, without cognitive possibilities to think about their conditions. This may possibly hinder transition to adulthood.

In this study, it was observed that without adult and educational supervision, cyber activities do not provide benefits to adolescents' lives, especially those from lower socio-economic classes, who lack appropriate supervision and guidance in the home and at school. It was also observed that, although 
most of the adolescents studied have access to ICT at home, they have not had the proper educational support to develop digital inclusion. Thus, educational intervention is essential as well as government policies regarding internet use to prevent children and adolescents from accessing inappropriate content. Educational intervention will allow students to gain critical insight into the internet and resist ideological manipulations that consistently trap adolescents within a narcissistic network of trivialities.

\section{Acknowledgements}

This work was supported by CAPES Coordenação de Aperfeiçoamento de Pessoal de Nível Superior, in Brazil.

\section{References}

[1, 26] S. Freud, Mal-estar da civilização, Imago, Rio de Janeiro, 1930/2010, p. 52.

[2, 4, 18, 22] G. Bradbrook and J. Fisher, "Digital Equality: Revewing digital inclusion activity and mapping the way forwads", $2004 . \quad$ Available from: http://www.citizensonline.org.uk/site/media/documents/939 Digital Equality1.pdf. [Accessed $20^{\text {th }}$ May 2011].

[3] A. Almuwil, V. Weerakkadyt, \& R. El-Haddadeh. "A conceptual study of the factors influencing e-inclusion", European, Mediterraean \& Middle Eastern Conference on Information Systems, Athens, 30-31/05/ 2011. Available from:

http://www.iseing.org/emcis/EMCISWebsite/EMCIS2011\%2 0Proceedings/GOV6.pdf. [Accessed $9^{\text {th }}$ January 2013].

[5] CGI.Br (Brazilian Internet Steering Committee), Survey on ICT Households and Enterprises 2010, São Paulo, 2011. Available from: www.cgi.br/publicacoes/pesquisas/index.htm. [Accessed 18 th October 2012].

[6, 15, 20, 21] CGI.Br (Brazilian Internet Steering Committe), ICT Education 2010: survey on the use of information and communication technologies in Brasilians Schools, São Paulo, 2011, p. 244. Available from: www.cgi.br/publicacoes/pesquisas/index.htm [Accessed $15^{\text {th }}$ May 2012].

[7] P. Lévy. A inteligência coletiva: por uma antropologia do ciberespaço, Edições Loyola, São Paulo, 1994.
[8, 27, 28] T. Adorno and, M. Horkheimer, La dialectique de la raison, Galimard, Paris, 1947/1974.

[9] T. Adorno, The culture industry: selected essays on mass culture. Routledge Classics, London and New York, 1975/1991, p.98.

[10, 23] R. Duarte, , "A indústria cultural hoje”: In Durão, F.A. and Zuin, A.F.V. A Indústria cultural hoje.: Boitempo, São Paulo, 2008.

[11, 31] D.-R.Dufour. The art of shrinking heads: the new servitude of the liberated in the era of total capitalism. Polity Press, Cambridge, 2008

[12, 29] B.Stiegler, , La télécratie contre la démocratie, Flamarion, Paris, 2006

[13, 28] B.Stiegler, , Prends soin de la jeunesse et des générations, Flamarion, Paris, 2008, p.47.

[14, 32] M.G.T. Amaral, A trama e a urdidura entre as culturas juvenis e a cultura escolar: a eróptica como método de pesquisa e de ruptura de campo. Tese de Livre-Docência defendida na Faculdade de Educação da USP, São Paulo,

[16] Ministério da Educação. UCA : Projeto um computador por aluno, Brasília, 2006. Available from: http://www.uca.gov.br/institucional/projeto.jsp [Accessed 10 ${ }^{\text {th }}$ September 2012].

[17] S.C.P. Meneses, UCA um computador por aluno: era da inclusão digital. In Anais do XXII SBIE, november 2011. Available from: http://ceiesbc.tempsite.ws/pub/index.php/sbie/article/view/1656/1421 [Accessed $09^{\text {th }}$ April 2013].

[19] Safernet e Ministério Público Federal do Rio de Janeiro, 2010. "Relatório da pesquisa online no Estado do Rio de Janeiro: Hábitos de navegação na Internet: será que nossos alunos e educadores navegam com segurança na internet no Estado do Rio de Janeiro?" Rio de Janeiro: Ministério Público Federal do Rio de Janeiro,2009. Available from: http://www.safernet.org.br/site/prevencao/pesquisa [Accessed $15^{\text {th }}$ January 2013].

[24] M. Hautefeuille and D. Véléa, Les addictions à internet : de l'ennui à la dépendance, Éditions Payot et Rivage, Paris, 2010

[25] M. Amorim, , Raconter, démontrer, survivre: formes de savoir et de dicours dans la culture contemporaine, Éditions Érès, Paris, 2007. 